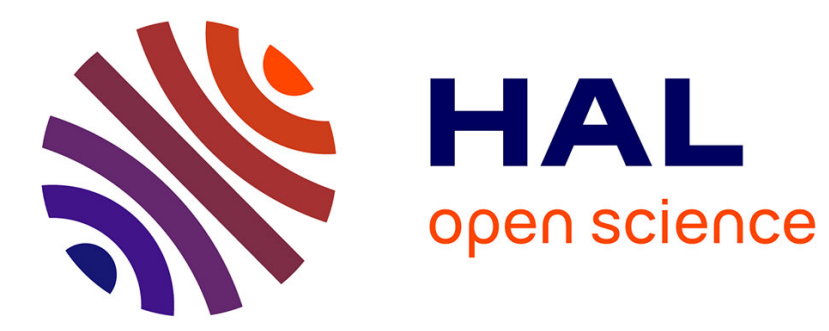

\title{
Strategies for Implementing Collaborative Robot Applications for the Operator 4.0
}

Åsa Fast-Berglund, David Romero

\section{To cite this version:}

Åsa Fast-Berglund, David Romero. Strategies for Implementing Collaborative Robot Applications for the Operator 4.0. IFIP International Conference on Advances in Production Management Systems (APMS), Sep 2019, Austin, TX, United States. pp.682-689, 10.1007/978-3-030-30000-5_83 . hal02419224

\section{HAL Id: hal-02419224 \\ https://hal.inria.fr/hal-02419224}

Submitted on 19 Dec 2019

HAL is a multi-disciplinary open access archive for the deposit and dissemination of scientific research documents, whether they are published or not. The documents may come from teaching and research institutions in France or abroad, or from public or private research centers.
L'archive ouverte pluridisciplinaire HAL, est destinée au dépôt et à la diffusion de documents scientifiques de niveau recherche, publiés ou non, émanant des établissements d'enseignement et de recherche français ou étrangers, des laboratoires publics ou privés. 


\title{
Strategies for Implementing Collaborative Robot Applications for the Operator 4.0
}

\author{
Åsa Fast-Berglund ${ }^{1[0000-0002-0524-7913]}$ and David Romero ${ }^{1-2[0000-0002-1685-4305]}$ \\ ${ }^{1}$ Chalmers University of Technology, Sweden \\ ${ }^{2}$ Tecnológico de Monterrey, Mexico \\ asa.fasth@chalmers.se; david.romero.diaz@gmail.com
}

\begin{abstract}
To accomplish a flexible and highly productive production system, collaborative robot applications, such as co-bots, can be one solution. Hence, last year: 2018 , less than $4 \%$ of the industrial robot investments had "collaborative roots". In order to increase this number, clear strategies for the implementation of co-bots are vital. This paper will present the results from the study of 40 SMEs, and six OEMs, regarding where and when to implement co-bots in production. Furthermore, which KPIs to consider when implementing these collaborative robot applications. The Lotus Blossom technique has been used to create the first steps towards strategies for implementing collaborative robot applications for the Operator 4.0. Seven areas of application have been pre-selected, and one area has been left free of choice for the companies. The results show that the areas with greater strategic interest are 'pick-n'-place' tasks and 'load-unload' tasks.
\end{abstract}

Keywords: Co-Bots, Collaborative Robots, Collaborative Applications, HumanRobot Interaction, SMEs, Industry 4.0, Operator 4.0, Production Systems.

\section{Introduction}

Automation technology was originally developed with the aim and hope of increasing the precision and economy of production operations while, at the same time, reducing the operators' workload and training requirements [1]. With the new (r)evolution of collaborative robots (co-bots), new possibilities and tasks situated 'side-by-side' or 'face-to-face' with the operators have increased [2]. Adaptive co-bots [3] combined with 'smart cognitive support' for the operator [4] can be one solution in order to increase human-robot interaction. The adaptive co-bots are 'dynamically adapting' to the human's pace, stress-level, and experience. This results in increased flexibility [5], decreased ergonomic related issues [6], and increased quality (i.e. 100\% Complete \& Accurate Assembly Tasks). So, the flexibility and changeability of assembly processes require a close linkage between the worker and the automated assembly system [7]. The operator needs to be skilled and performing 'cooperative work' with robots, and other machines and cyber-physical systems, e.g. The (Collaborative) Operator $4.0[8,9]$. 
Hence, according to the IFR ${ }^{1}$, industrial robots have been increasing their presence at the shop-floors with over $10 \%$ per year over the last years, but less than $4 \%$ of the total investments have been in collaborative robots. SMEs want to implement 'co-bots', but the lack of clear strategies makes it hard to understand where and when to implement a human-robot collaboration solution, and how to show a Return of Investment (ROI) for the top management. This paper will present a study made with 46 Swedish companies, both SMEs and OEMs, on how to create strategies for collaborative robot applications by using a creative technique known as "Lotus Blossom".

\section{Designing Collaborative Human-Robot Workplaces}

When designing a collaborative human-robot workplace, a series of design guidelines must be considered in order to obtain acceptable, successful design solutions. These can be divided into the following five design criterions [10]: (i) operational efficiency, (ii) safety [11], (iii) ergonomics, (iv) development of the work content and work organization, and (v) acceptance or trust in automation [12]. A collaborative humanrobot workspace is defined as a shared space within the operating space where the robot system, including the workpiece, and a human can perform tasks concurrently during a production operation [13-15]. The robot system, or co-bot, within this system is defined as a robot designed for direct interaction with a human within the defined collaborative workspace [13]. Hence, different research works show that a direct interaction between humans and co-bots is hard to accomplish and that a division of several levels of interaction is easier to implement $[2,10,16]$. The two lowest levels of human-robot interaction are: (i) co-existence - where the human and the co-bot are located close to each other, but separated without overlapping each other's workspace, and therefore tasks, and (ii) synchronization - where the human and the co-bot share the workspace, but there is no direct contact between them in a step-by-step process of human and cobot sequential tasks. These two (low) levels of interaction are the ones more commonly used today in industrial applications. Whereas the two higher levels of human-robot interaction are: (iii) cooperation - where the human and the co-bot share the same workspace with direct contact, if necessary, and also share the work task in a sequential process, and (iv) collaboration - where the human and the co-bot share the same workspace with direct contact, and share the work task in a simultaneous process. These two (high) levels of interaction are more commonly used in R\&D lab environments [7].

In order to achieve a human-centered approach [17] towards automation [18], 'task allocation' strategies are fundamental. The task to be accomplished sets the tone for the system's design and use when discussing human-robot interactions [19]. The assembly tasks need to be well defined in order to fully understand where and when the interaction between humans and co-bots will take place, how to design collaborative human-robot workspaces [20], and how to create future strategies and scenarios. Consensus between managers and operators [21] is also essential in order to ramp-up the implementation of collaborative robot applications. Highly skilled operators that can interact with the co-bots, and other systems, is also indispensable, e.g. The Operator 4.0 [8]. Depending

\footnotetext{
${ }^{1}$ International Federation of Robotics (IFR) - https://ifr.org/
} 
on what type of human-robot interaction combinations [19] the workforce choose, different issues need to be considered and addressed.

Moreover, in order to fully realize the benefits of collaborative robot applications, a combination of other enabling Industry 4.0 technologies [22] and organizational practices is needed. For example, the Internet of Industrial Things (IIoT) [23], human cyber-physical systems [8] and softbots [24] combined with skilled operators and novel work structures can make the co-bots applications even more flexible, adoptable, and interactive.

In order to create a 'Robotics \& Automation (R\&A)' strategy for companies that still are in the Industry 3.0 era, a simple start is recommended. Co-bots were the first choice for the SMEs within the conducted study. The most common reason was that they have already worked with robots before, and they saw the benefits of investing in them.

\section{$3 \quad$ Methodology}

To create a collaborative human-robot workplace it is important to understand where (i.e. in which area within the manufacturing system) and when to implement the collaborative robot application (i.e. the co-bot). The companies tend to choose too complex tasks to automate and too high levels of interaction. To generate concrete cases for automation, the Lotus Blossom technique was used for the case companies. The Lotus Blossom technique is especially useful for generating strategic scenarios [25] and it was tested at the case companies to see if it could be utilized as a first step towards defining their R\&A strategies. The technique is used to increase creative thinking [26] and to understand and decrease the boundaries of knowledge sharing [27]. The technique begins with a central core idea or central theme, in this case, the core idea/word is 'collaborative robot applications', which is surrounded by an everexpanding set of related ideas, like the petals of a 'Lotus Blossom' (see Fig.1).

Fig. 1 shows a stepwise example. First, we have a core idea: Collaborative Robot Applications. Then, we choose different KPIs that can be used to measure the selected application impact: Joining Task - Quality Improvement. Finally, we rank the different KPI parameters to be measured: Quality Parameters - e.g. First Time Through (FTT).

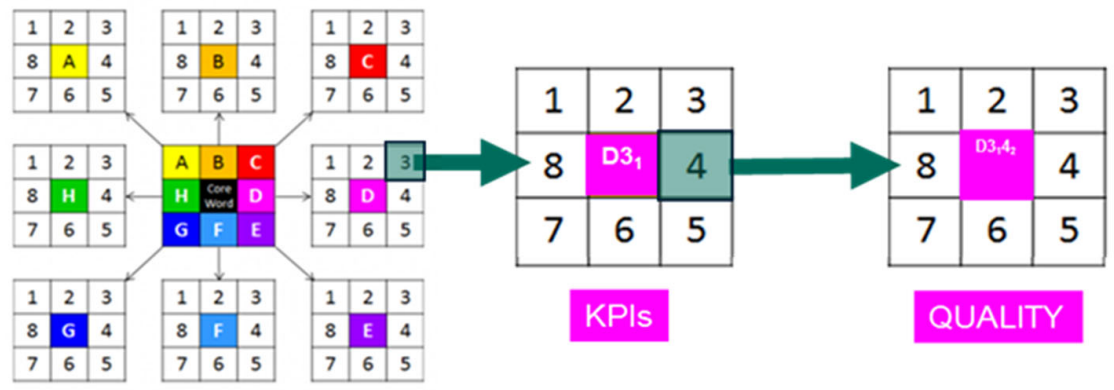

Fig. 1. Lotus Blossom Technique Steps 
In this paper three sets of related ideas or rounds have been conducted:

- Step 1 - Identify and Rank Collaborative Robot Applications: Which tasks do the case companies want to automate? Seven collaborative robot applications have been identified as the most common to start with, and are presented in Section 3.1.

- $\quad$ Step 2 - Identify Different Areas for the Collaborative Robot Applications: Which area of the manufacturing system do companies want to automate? Sometimes the same type of task can be applied in many different areas, for example, a 'pick-n'-place' task can be applied in both final assembly and manufacturing operations.

- Step 3 - Identify KPIs for the Collaborative Robot Applications: Which parameters can be measured to prove the improvements offered by the automation solution of the selected tasks?

\subsection{Identifying Collaborative Robot Applications - through a Literature Review and Interviews with Robot Integrators (Step 1.1)}

To identify the first seven areas, i.e. Tasks for Automation, to be used in the Lotus Blossom, a small literature review and interviews with the five largest robot integrators in Sweden were conducted. The seven areas or tasks are described in Table 1.

Table 1. Common Applications for Collaborative Robots

\begin{tabular}{|c|l|}
\hline Area/Task & \multicolumn{1}{c|}{ Description } \\
\hline $\begin{array}{c}\text { Pre- } \\
\text { assembly }\end{array}$ & $\begin{array}{l}\text { Pre-assembly robots/co-bots use their part handling, high-speed picking, and } \\
\text { assembly capabilities to assemble parts and components into sub-assemblies, } \\
\text { freeing up the operators to do other more value-added tasks at the assembly } \\
\text { line. }\end{array}$ \\
\hline Inspection & $\begin{array}{l}\text { Inspection robots/co-bots use their computer vision capability to evaluate the } \\
\text { conditions of a part or a product in a very short-time and with higher } \\
\text { accuracy when compared with humans'vision. }\end{array}$ \\
\hline Kitting & $\begin{array}{l}\text { Kitting robots/co-bots combine their coordinated computer vision with their } \\
\text { picking-n'-placing capabilities to identify individual parts or products and } \\
\text { assemble them in specific kits (assortments). }\end{array}$ \\
\hline Joining & $\begin{array}{l}\text { Joining robots/co-bots hold a welding torch or a glue gun and use their } \\
\text { precision capabilities to deposit material at a constant rate and in a fixed } \\
\text { path. }\end{array}$ \\
\hline $\begin{array}{c}\text { Final } \\
\text { Assembly }\end{array}$ & $\begin{array}{l}\text { Final Assembly robots/co-bots use their part handling, high-speed picking, } \\
\text { and assembly capabilities to assemble final assemblies into a final product. }\end{array}$ \\
\hline Packing & $\begin{array}{l}\text { Packing (n' Palletizing) robots/co-bots use their handling capabilities for } \\
\text { shrink-wrapping, box assembly and loading, and box collating or placing } \\
\text { onto a pallet for shipping. }\end{array}$ \\
\hline Pick-n'- \\
Place
\end{tabular} \begin{tabular}{l}
$\begin{array}{l}\text { Pick-n'-Place robots/co-bots use their part handling and high-speed picking } \\
\text { capabilities to place a part in a different location. Manual pick-n'-place is } \\
\text { one of the most repetitive tasks performed by human workers today. }\end{array}$ \\
\hline
\end{tabular}


An additional area/task called: "own choice', was added during the workshop in order to increase the motivation and creativity of the participants, and it is illustrated as ' $\mathrm{F}$ ' in Fig. 2.

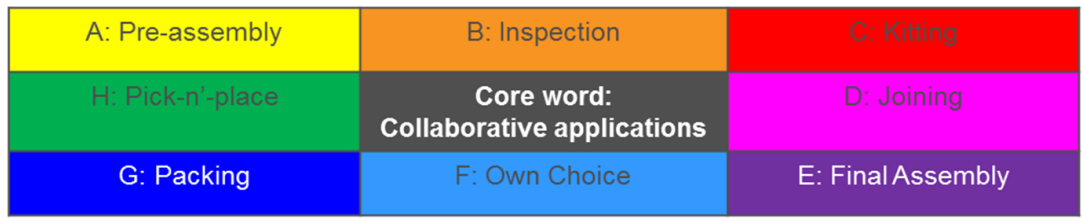

Fig. 2. The First Seven +1 Areas with the Core Word: Collaborative Robot Applications

\subsection{Ranking Collaborative Robot Applications (Step 1.2)}

Seven workshops were conducted during 2018-2019 with a total of 46 companies, 40 SMEs and six OEMs. The SMEs were mainly small companies that had between 10 to 50 employees and were mostly sub-contractors $(70 \%)$ or had their own special niche (30\%) (see Table 2).

Table 2. Workshops within Collaborative Robot Applications

\begin{tabular}{|c|c|c|c|c|}
\hline \multicolumn{2}{|c|}{ Workshop } & \multicolumn{3}{c|}{ No. of Participants } \\
\hline 2018 & 2019 & OEM & SMEs & Persons \\
\hline 1 & & 1 & 6 & 27 \\
\hline 2 & & 0 & 5 & 14 \\
\hline & 3 & 2 & 7 & 18 \\
\hline & 4 & 0 & 5 & 12 \\
\hline & 5 & 0 & 8 & 22 \\
\hline & 6 & 2 & 5 & 16 \\
\hline & 7 & 1 & 4 & 25 \\
\hline
\end{tabular}

At each workshop, the companies ranked the seven +1 areas, illustrated in Table 3, in two different ways:

1. Importance for the companies, and

2. Time horizon for implementation.

Table 3. Ranking of Collaborative Robot Applications Areas

\begin{tabular}{|c|l|l|}
\hline Ranking & \multicolumn{1}{|c|}{ Level of Importance } & Time Horizon for Implementation \\
\hline 1 & Very Important & $<2$ years \\
\hline 2 & Important & $3-5$ years \\
\hline 3 & Medium Important & $6-10$ years \\
\hline 4 & Less Important & $>10$ years \\
\hline 5 & Not part of our Company's Tasks & Never \\
\hline
\end{tabular}


Table 4 shows the average ranking of each area in each workshop and the overall average of the workshops at the bottom line.

Table 4. Results from the $1^{\text {st }}$ Step of the Lotus Blossom Technique

\begin{tabular}{|c|c|c|c|c|c|c|c|c|c|c|c|c|c|c|c|c|c|}
\hline \multicolumn{1}{|c|}{$\begin{array}{c}\text { Level of Importance } \\
\text { Workshop }\end{array}$} & \multicolumn{4}{c|}{$\begin{array}{c}\text { Time Horizon for } \\
\text { Implementation (Average) }\end{array}$} \\
\hline 2018 & 2019 & A & B & C & D & E & F & G & H & A & B & C & D & E & F & G & H \\
\hline X & & 4 & 2 & 4 & 5 & 3 & 3 & 2 & 2 & 4 & 3 & 4 & 5 & 3 & 3 & 2 & 2 \\
\hline $\mathrm{X}$ & & 4 & 2 & 3 & 2 & 3 & 5 & 1 & 1 & 4 & 2 & 3 & 2 & 3 & 5 & 3 & 2 \\
\hline & $\mathrm{X}$ & 2 & 2 & 2 & 4 & 3 & 4 & 2 & 2 & 2 & 3 & 3 & 3 & 3 & 4 & 3 & 3 \\
\hline & $\mathrm{X}$ & 3 & 3 & 3 & 4 & 4 & 3 & 2 & 2 & 3 & 2 & 3 & 3 & 3 & 4 & 3 & 2 \\
\hline & $\mathrm{X}$ & 2 & 2 & 3 & 3 & 3 & 3 & 2 & 2 & 2 & 3 & 3 & 4 & 3 & 3 & 4 & 3 \\
\hline & $\mathrm{X}$ & 2 & 2 & 3 & 3 & 2 & 2 & 2 & 2 & 2 & 2 & 3 & 3 & 3 & 2 & 3 & 2 \\
\hline & $\mathrm{X}$ & 3 & 3 & 3 & 2 & 4 & 3 & 3 & 2 & 3 & 3 & 3 & 3 & 4 & 4 & 3 & 3 \\
\hline & $\mathbf{5}$ & $\mathbf{3}$ & $\mathbf{2}$ & $\mathbf{3}$ & $\mathbf{4}$ & $\mathbf{3}$ & $\mathbf{3}$ & $\mathbf{2}$ & $\mathbf{2}$ & $\mathbf{3}$ & $\mathbf{3}$ & $\mathbf{3}$ & $\mathbf{3}$ & $\mathbf{3}$ & $\mathbf{4}$ & $\mathbf{3}$ & $\mathbf{2}$ \\
\hline
\end{tabular}

\subsection{Identifying Different Areas for Collaborative Robot Applications (Step 2)}

A trend was that when there were OEM companies participating in the workshops, 'PreAssembly' and 'Final Assembly' tasks were ranked higher. While the SMEs tended to rank 'Pick-n'-Place' and 'Load-Unload' tasks higher (see Table 4).

The areas/tasks that were ranked as the highest of the seven +1 were the collaborative robot applications: $\mathrm{H}(2: 2)$ and $\mathrm{B}(2: 3)$, i.e. Inspection and Pick-n'-Place tasks (including Load-Unload tasks) (see Table 4). The SMEs often had machining tasks as their primary tasks as they were producing components as sub-contractors for the OEMs. This is one reason for the high ranking of 'Load-Unload' tasks. Another explication could be that these tasks have a lower level of human-robot interaction, often 'co-existence' or 'synchronized', and therefore, made it easier to start with.

Most of the companies that have not implemented collaborative robot applications yet, had a time horizon of 3 to 5 years before they thought that they will have an implemented application. The reasons for this were management and financial issues. A common misconception was that robots still are too expensive to buy (see Table 3).

The lowest ranked areas/tasks were $\mathrm{D}(4: 3)$ and $\mathrm{F}(3: 4)$, i.e. Joining and Own Choice (see Table 4). The 'joining', e.g. gluing, welding, etc. was better off for traditional industrial robots according to most of the companies. One important factor was the safety around the manufacturing cell.

After the first round, the case companies had one up to eight different scenarios that they wanted to investigate further in terms of collaborative robot applications, and $10 \%$ had already invested in a co-bot and had started to implement it. These implementations were 'Load-Unload' tasks into CNC-, Drilling-, and Milling- operations. 


\subsection{Identifying KPIs for Collaborative Robot Applications (Step 3)}

The most common KPIs for the case companies were: (i) to increase ergonomics, (ii) to have a more even cycle time, (iii) to increase quality, and (iv) to increase resource- and volume- flexibility.

\section{Conclusions}

To implement collaborative robot applications successfully, a clear $R \& A$ strategy is important. The results from the workshops show that the case companies do not have the expertise in where and what to implement. Collaborative robots tend to be the first enabling technology within Industry 4.0 that SMEs chose to implement. There is also a tendency towards implementing Additive Manufacturing as a second step, mostly to print fixtures or grippers for the co-bots. Combining Collaborative Robots with other enabling technologies such as IIoT, Artificial Intelligence, or Augmented Reality will make collaborative robot applications even more effective and efficient when it comes to quality assurance and time-efficiency in programming.

\section{Acknowledgement}

This research is conducted in cooperation with RISE-IVF, the IUC network, and Production 2030. For economical support, the authors acknowledge Vinnova and Stena Industry Innovation lab.

\section{References}

1. Sarter, N.B., Woods D.D., Billings, C.E.: Automation Surprises. Handbook of Human Factors and Ergonomics, Publisher: John Wiley and Sons (1997)

2. Wang, X.V. et al.: Human-Robot Collaborative Assembly in Cyber-Physical Production: Classification Framework and Implementation. CIRP Annals, 66(1):5-8 (2017)

3. G, O.C. et al.: Social Co-bots: Anticipatory Decision-Making for Collaborative Robots Incorporating Unexpected Human Behaviors. Proceedings of the ACM/IEEE International Conference on Human-Robot Interaction, Chicago, IL, USA. pp. 398-406 (2018)

4. Romero, D., Mattsson, S., Fast-Berglund, Å., Wuest, T., Stahre, J., Gorecky, D.: Digitalizing Occupational Health, Safety and Productivity for the Operator 4.0. Production Management for Data-Driven, Intelligent, Collaborative, and Sustainable Manufacturing. IFIP AICT, Vol. 536, pp. 473-481, Springer (2018)

5. Matthias, B., et al.: Safety of Collaborative Industrial Robots: Certification Possibilities for a Collaborative Assembly Robot Concept. IEEE International Symposium on Assembly and Manufacturing (2011)

6. Fast-Berglund, Å., Palmkvist, F., Nyqvist, P., Ekered, S., Åkerman, M.: Evaluating Cobots for Final Assembly. Procedia CIRP, Vol. 44, pp. 175-180 (2016)

7. Krüger, J., Lien, T.K., Verl, A.: Cooperation of Human and Machines in Assembly Lines. CIRP Annals, 58(2):628-646 (2009) 
8. Romero, D., Stahre, J., Wuest, T., Noran, O., Bernus, P., Fast-Berglund, Å., Gorecky, D.: Towards an Operator 4.0 Typology: A Human-Centric Perspective on the Fourth Industrial Revolution Technologies. International Conference on Computers \& Industrial Engineering, Tianjin/China, pp. 1-11 (2016)

9. Romero, D., Bernus, P., Noran, O., Stahre, J., Fast-Berglund, Å.: The Operator 4.0: Human Cyber-Physical Systems \& Adaptive Automation towards Human-Automation Symbiosis Work Systems. Initiatives for a Sustainable World. IFIP AICT, Vol. 488, pp. 677-686. Springer (2016)

10. Bauer, W. et al.: Lightweight Robots in Manual Assembly - Best to Start Simply!. Fraunhofer Institute for Industrial Engineering (IAO) (2016)

11. Djuric, A.M., Urbanic, R.J., Rickli, J.L.: A Framework for Collaborative Robot (CoBot) Integration in Advanced Manufacturing Systems. SAE International Journal of Materials and Manufacturing, 9(2):457-464 (2016)

12. Hoffman, R.R. et al.: Trust in Automation. IEEE Intelligent Systems, 28(1):84-88 (2013)

13. ISO 10218-1: Robots and Robotic Devices -- Safety Requirements for Industrial Robots -Part 1: Robots (2011)

14. ISO 10218-2: Robots and Robotic Devices -- Safety Requirements for Industrial Robots -Part 2: Robot Systems and Integration (2011)

15. ISO/TS 15066: Robots and Robotic Devices -- Collaborative Robots (2016)

16. Thomas, C. et al.: Intuitive Work Assistance by Reciprocal Human-Robot Interaction in the Subject Area of Direct Human-Robot Collaboration. Procedia CIRP, Vol. 44, pp. 275-280 (2016)

17. Billings, C.E.: Aviation Automation: The Search for a Human-Centered Approach, CRC Press (1996)

18. Sheridan, T.B.: Human Centered Automation: Oxymoron or Common Sense?. IEEE International Conference on Systems, Man and Cybernetics. Intelligent Systems for the 21st Century (1995)

19. Yanco, H.A., Drury J.: Classifying Human-Robot Interaction: An Updated Taxonomy. IEEE International Conference on Systems, Man and Cybernetics (Cat. No. 04CH37583) (2004)

20. Fasth-Berglund, Å., Stahre J.: Cognitive Automation Strategy for Reconfigurable and Sustainable Assembly Systems. Assembly Automation, 33(3):294-303 (2013)

21. Mirzaei, N.E. et al.: Strategic Consensus on Manufacturing Strategy Content. International Journal of Operations \& Production Management, 36(4):429-466 (2016)

22. Bortolini, M. et al.: Assembly System Design in the Industry 4.0 Era: A General Framework. IFAC-PapersOnLine, 50(1):5700-5705 (2017)

23. Åkerman, M., Fast-Berglund, Å.: Interoperability for Human-Centered Manufacturing. OTM 2017 Lecture Notes in Computer Science, Vol. 10697, pp 76-83 (2017)

24. Boesl, D.B.O., Liepert. B.: Robotic Revolutions - Proposing a Holistic Phase Model Describing Future Disruptions in the Evolution of Robotics and Automation and the Rise of a New Generation 'R' of Robotic Natives. IEEE/RSJ International Conference on Intelligent Robots and Systems (2016)

25. Higgins, J.M.: Innovate or Evaporate: Creative Techniques for Strategists. Long Range Planning, 29(3):370-380 (1996)

26. Petruţa, G.-P.: Teacher's Opinion on the Use of Interactive Methods/Techniques in Lessons. Procedia - Social and Behavioral Sciences, Vol. 76, pp. 649-653 (2013)

27. Van Dong, P., Hawryszkiewycz, I., Binsawad, M.H.: Classifying Knowledge-Sharing Barriers by Organisational Structure in order to Find Ways to Remove these Barriers. 8th International Conference on Knowledge and Systems Engineering (2016) 